\title{
BMJ Open Risk marker associations with venous thrombotic events: a cross-sectional analysis
}

\author{
Beatrice A Golomb, ${ }^{1,2}$ Virginia T Chan, ${ }^{1,3}$ Julie O Denenberg, ${ }^{2}$ Sabrina Koperski, ${ }^{1}$ \\ Michael H Criqui ${ }^{1}$
}

To cite: Golomb BA, Chan VT, Denenberg J0, et al. Risk marker associations with venous thrombotic events: a crosssectional analysis. BMJ Open 2014;4:e003208.

doi:10.1136/bmjopen-2013003208

- Prepublication history for this paper is available online. To view these files please visit the journal online (http://dx.doi.org/10.1136/ bmjopen-2013-003208).

BAG and VTC shared first authorship.

Received 7 June 2013 Revised 8 November 2013 Accepted 11 November 2013

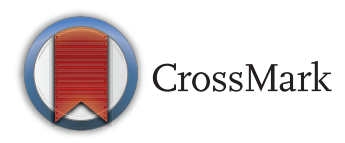

${ }^{1}$ Department of Medicine, University of California San Diego, La Jolla, California, USA

${ }^{2}$ Department of Family and Preventive Medicine, University of California San Diego, La Jolla, California, USA

${ }^{3}$ Internal Medicine, Scripps Green Hospital, La Jolla, California, USA

\section{Correspondence to} Beatrice A Golomb; bgolomb@ucsd.edu

\section{ABSTRACT}

Objective: To examine the interrelations among, and risk marker associations for, superficial and deep venous events-superficial venous thrombosis (SVT), deep venous thrombosis (DVT) and pulmonary embolism (PE).

Design: Cross-sectional analysis.

Setting: San Diego, California, USA.

Participants: 2404 men and women aged 4079 years from four ethnic groups: non-Hispanic White, Hispanic, African-American and Asian. The study sample was drawn from current and former staff and employees of the University of California, San Diego and their spouses/significant others.

Outcome measures: Superficial and deep venous events, specifically SVT, DVT, PE and combined deep venous events (DVE) comprising DVT and PE.

Results: Significant correlates on multivariable analysis were, for SVT: female sex, ethnicity (AfricanAmerican=protective), lower educational attainment, immobility and family history of varicose veins. For DVT and DVE, significant correlates included: heavy smoking, immobility and family history of DVEs (borderline for DVE). For PE, significant predictors included immobility and, in contrast to DVT, blood pressure (BP, systolic or diastolic). In women, oestrogen use duration for hormone replacement therapy, in all and among oestrogen users, predicted PE and DVE, respectively.

Conclusions: These findings fortify evidence for known risk correlates/predictors for venous disease, such as family history, hormone use and immobility. New risk associations are shown. Striking among these is an association of PE, but not DVT, to elevated BP: we conjecture PE may serve as cause rather than consequence. Future studies should evaluate the temporal direction of this association. Oxidative stress and cell energy compromise are proposed to explain and predict many risk factors, operating through celldeath mediated triggering of coagulation activation.

\section{INTRODUCTION}

Chronic venous disease causes significant morbidity in diverse populations around the

\section{Strengths and limitations of this study}

- Recall may be imperfect and fatal events are not included.

- Cross-sectional design does not define temporality in venous event/risk marker relations.

- On the positive side, this cross-sectional design may enable relationships to be identified that arise from effects of 'events' on physiological variables: such relations may also be important, and may be missed in prospective studies that censor follow-up at the occurrence of an event. Longitudinal assessment, continued after PE occurrence, is required to confirm the conjectured directionality of the observed association.

world $^{1-5}$ and costs are material, with estimates suggesting that up to several per cent of total healthcare expenditures are linked to venous disorders. ${ }^{2}{ }^{6-9}$ Considerable time and resources are devoted to venous conditions in clinical practice. The San Diego Population Study (SDPS) has sought to better define venous disease prevalence and epidemiology ${ }^{10}{ }^{11}$ by clearly delineating and separately analysing risk correlates for different elements of venous disease, irrespective of the directionality of the association. The present report pertains to a history of venous thrombotic events, including superficial venous thrombosis (SVT), deep venous thrombosis (DVT) and pulmonary embolism $(\mathrm{PE})$. It assesses the relation of age, sex and other potential risk factors to a history of these events.

\section{MATERIALS AND METHODS}

Subjects

A total of 2404 men and women aged 4079 years from four ethnic groups (nonHispanic White, Hispanic, African-American and Asian), comprising current and former staff/employees of the University of California, San Diego and their spouses/significant 
others, were targeted for participation in the SDPS. Inclusion of spouses/significant others modestly extended the age range of participants (29-91 years). Participants represented a spectrum of socioeconomic status, including the unemployed and retired as well as working persons. A description of the SDPS population, for which collected data from 1994 to 1998 , is available elsewhere. ${ }^{10}$ The study's primary aims related to prevalence, and the study was powered such that $95 \%$ confidence limits for prevalence for each sex were less than $\pm 3.3 \%$; and for subgroups of, for example, $n=200$, less than $\pm 7 \%$. The study was approved by the UCSD Human Research Protections Program, and all participants gave written informed consent.

\section{Outcomes}

SVT, DVT and PE were ascertained by self-report. Questions elicited a history of "a blood clot in a leg vein" and "phlebitis or inflamed vein in your leg," stratified by whether the problem was in a superficial or deep vein and queried separately for each leg; "pulmonary embolism or blood clot in lung" and "heparin or coumadin/warfarin therapy for a problem with your veins". Because PEs are pathophysiologically linked to DVTs, DVT and PE were analysed separately and conjointly as deep venous events (DVEs: DVT and/or PE).

\section{Independent variables}

Variables evaluated for their relation to SVT, DVT, PE and DVE included self-reported age, sex, ethnicity, smoking status, alcohol consumption, self-reported activity level, education level (ranked from $1=$ grade school or less to $9=$ doctoral degree), occupation (categorical), hormone use in women including oral contraceptive use (and if so, number of years); and postmenopausal hormone replacement therapy (HRT) use (and if so, number of years) and history of immobility (ie, bed-rest) for $>1$ day. Assessment of family history of venous events inquired regarding each qualifying venous condition in each firstdegree relative (parents, siblings, children), such that a positive family history of DVEs required one or more qualifying DVE in one or more first-degree relatives. Systolic and diastolic brachial blood pressure (SBP and DBP, respectively) were assessed using the participant's right arm after the participant sat quietly for $5 \mathrm{~min}$. Ethnicity, determined by self-report, was categorised as above as non-Hispanic White (hereafter referred to as Caucasian), Hispanic, African-American or Asian. Alcohol measures examined included drinking status (none vs present), days per week of alcohol consumption and highest number of drinks in a day. Smoking information included current smoking status, years of smoking, average packs/day during time smoked (allowing calculation of pack years of smoking) and heavy smoker status (defined as $\geq 40$ cigarettes/day average during time smoked). Activity was coded into five levels, assessed relative to others of the same age and sex. Responses ranged from "much less active" to "much more active". In analyses examining venous outcomes in women, oestrogen use duration and other hormone measures were also evaluated as potential risk factors.

\section{Analyses}

Participant characteristics were tabulated as a function of venous event status-no event, SVT, DVT or PE. The unadjusted relationship of demographic and potential risk variables to each event type was ascertained, using the $\mathrm{t}$ test of difference in mean values for continuous variables and $\chi^{2}$ testing for categorical variables. Relationships between SVT, DVT and PE were also evaluated.

For multivariable analyses, following the examination of correlations among predictor variables to assist in assessing issues of collinearity, logistic regression was performed. Age and sex-adjusted regressions were followed by multivariable regressions including all variables for which a relationship was supported in bivariable analysis (full model). Where several measures tapping the same variable were appraised, for example, pack years of smoking versus heavy smoking, the variable that bore the stronger apparent relationship to the outcome was employed in multivariable analyses. A 'final' regression model was then determined for each venous event outcome, adjusted for potential predictor variables identified from bivariable and age-sex adjusted or fully adjusted analyses. This assessed the multivariable relationship of candidate risk factors to events, controlling for potential confounders. Variables that approached significance on age-sex adjusted and/or fully adjusted analysis $(\mathrm{p}<0.2)$ were tested for inclusion in the final model. Those retaining potential predictive value $(\mathrm{p}<\sim 0.2)$ were retained in the final model. All logistic regression analyses were performed with and without stratification by sex; results of stratified analyses are presented only where effect modification by sex was present.

Sensitivity analyses were conducted adding back nonsignificant variables, but typically the final model variables were robustly supported (with exceptions specified). Significance was designated as two-sided $\mathrm{p}<0.05$. Analyses employed Stata V.8.0 (College Station, Texas, USA).

\section{RESULTS}

\section{Population characteristics}

Sixty-six per cent of participants were women (1580 women vs $824 \mathrm{men}$ ). Female participants were minimally but significantly younger on average than men (58.9 vs 60.1 years; $\mathrm{p}=0.012$ ). Average values of predictor variables in this population, stratified by venous event status, are shown in tables 1 and 2. Variables that differed significantly in those with SVT versus no events (on unadjusted analysis) were male sex, African-American ethnicity (protective), lower education level, drinkers who did not specify maximum alcohol consumption and family history of venous disease. For DVT, significant factors were age, Caucasian ethnicity (with African-American 
Table 1 Summary of demographic and predictor variables by venous event status (continuous variables)

\begin{tabular}{|c|c|c|c|c|}
\hline Variables & $\begin{array}{l}\text { No event } \\
\mathrm{N}=2262 \\
\text { Mean (SD) }\end{array}$ & $\begin{array}{l}\text { SVT } \\
\mathrm{N}=63 \\
\text { Mean (SD) }\end{array}$ & $\begin{array}{l}\text { DVT } \\
\text { N=74 } \\
\text { Mean (SD) }\end{array}$ & $\begin{array}{l}\text { PE } \\
\mathrm{N}=21 \\
\text { Mean (SD) }\end{array}$ \\
\hline Age & $59.1(11.4)$ & $60.5(10.7)$ & $61.9(11.7)^{*}$ & $61.5(10.2)$ \\
\hline Education† & $5.78(1.73)$ & $5.11(1.89)^{\star \star \star}$ & $5.73(1.67)$ & $5.29(1.79)$ \\
\hline Highest number of drinks per day & $2.70(3.13)$ & $2.24(2.51)$ & $3.32(3$ & $3.06(2$ \\
\hline Cigarettes/day averaged over years totalled $\ddagger$ & $6.99(11.5)$ & $7.73(14.1)$ & $12.0(16.1)^{\star \star \star}$ & $13.2(14.9)^{\star}$ \\
\hline Pack years§ & $7.22(14$ & 7. & $13.9(22.3)^{\star \star \star}$ & $9)^{\star \star}$ \\
\hline $\mathrm{SBP}(\mathrm{mm} \mathrm{Hg})$ & $131(20.3)$ & $132(22$ & $133(20.9)$ & $143.0(2$ \\
\hline DBP (mm Hg) & $76.8(11.3)$ & $76.6(10.8)$ & $78.2(9.67)$ & $82.5(7.69)^{\star}$ \\
\hline Total cholesterol (mg & $210(41.3)$ & 20 & & 209 \\
\hline HDL (mg/dL) & $54.5(17.0)$ & $51.4(11.3)$ & $50.9(15.6)$ & 49.9 (16.5) \\
\hline Activity levelף & $3.71(1.16)$ & 3.6 & 3.5 & 3.40( \\
\hline $\begin{array}{l}\text { Number of times in a week engaging in } \geq 20 \text { min of vigorous } \\
\text { activity }\end{array}$ & $3.60(2.51)$ & $3.78(2.66)$ & $3.52(2.53)$ & $3.40(2.54)$ \\
\hline Longest period of immobility (days) & 11. & 5.3 & & 31 \\
\hline $\begin{array}{l}\text { Oestrogen use duration for HRT among all females†† } \\
\text { (years) }\end{array}$ & $0.743(3.73)$ & $0.882(3.04)$ & $(1.60)$ & $(13.9)^{\star \star \star}$ \\
\hline \multicolumn{5}{|c|}{$\begin{array}{l}{ }^{*} p<0.05 ;{ }^{* *} p<0.01 ;{ }^{* \star *} p<0.001 \text {. } \\
\text { †Ordinal rather than continuous: ranked from } 1=\text { grade school or less to } 9=\text { doctoral degree. } \\
\text { †This correlated well with pack years, which showed a similar relationship to venous events; but variable transformations more suitably } \\
\text { satisfied regression constraints for this variable, and the impact of this variable was more potent than that of pack years for deep events, the } \\
\text { category of events for which it was predictive. } \\
\S \text { Pack years was calculated by multiplying years smoked by the average number of cigarettes per day divided by } 20 \text { (the average number of } \\
\text { cigarettes in one pack). } \\
\text { IRated relative to others your age, } 1-5 \text { with } 5 \text { being most active. } \\
\text { ††Only women were included in this portion of the analysis. } \\
\text { DBP, diastolic blood pressure; DVT, deep venous thrombosis; HDL, high-density lipoprotein; HRT, postmenopausal hormone replacement } \\
\text { therapy; PE, pulmonary embolism; SBP, systolic blood pressure; SVT, superficial venous thrombosis. }\end{array}$} \\
\hline
\end{tabular}

ethnicity somewhat protective), family history of venous disease, heavy smoking and high maximum alcohol consumption ( $\geq 7$ drinks/day). For PE, significant factors were heavy smoking, Caucasian ethnicity, SBP, DBP; and among women, oestrogen use duration for HRT among all women.

Table 2 Summary of demographic and predictor variables by venous event status (categorical variable)

\begin{tabular}{|c|c|c|c|c|}
\hline Variables & No event (\%) & SVT (\%) & DVT (\%) & PE (\%) \\
\hline Male & 34.5 & $19.0^{\star \star}$ & 35.1 & 42.9 \\
\hline Hypertension† & 35.9 & 28.6 & 32.4 & 42.9 \\
\hline Drinker (any alcohol) & 93.4 & 87.3 & 95.9 & 90.5 \\
\hline Maximum alcohol consumption $\geq 7$ drinks per day & 7.42 & 7.31 & $14.3^{*}$ & 16.7 \\
\hline Drinkers who did not specify maximum level of alcohol consumption & 8.49 & $22.6^{\star \star \star}$ & 11.1 & 10.5 \\
\hline Current smoker & 6.02 & 3.17 & 9.46 & 9.52 \\
\hline Heavy smoker ( $\geq 40$ cigarettes per day during time smoked) & 3.85 & 3.17 & $14.9^{\star \star \star}$ & $14.3^{*}$ \\
\hline \multicolumn{5}{|l|}{ Ethnicity } \\
\hline Caucasian & 58.9 & 65.1 & $78.4^{\star \star \star}$ & $81.0^{*}$ \\
\hline Hispanic & 14.7 & 20.6 & 9.46 & 4.76 \\
\hline African-American & 13.9 & $4.76^{\star}$ & $8.11^{*}$ & 9.52 \\
\hline Asian & 12.5 & 9.52 & 4.05 & 4.76 \\
\hline \multicolumn{5}{|l|}{ Occupation } \\
\hline Professional & 26.4 & 21.1 & 26.1 & 20.0 \\
\hline Technical, administrative or managerial & 40.9 & 38.6 & 40.6 & 45.0 \\
\hline Clerical and skilled & 26.8 & 29.8 & 30.4 & 25.0 \\
\hline Semiskilled & 3.85 & 8.77 & 2.90 & 5.00 \\
\hline Labourer & 2.07 & 1.75 & 0.00 & 5.00 \\
\hline Family history of venous diseases (venous condition in any first-degree relative) & 57.2 & $76.2^{\star \star}$ & $71.6^{*}$ & 57.1 \\
\hline Oral contraceptive use (ever; women) & 58.1 & 56.0 & 54.4 & 58.3 \\
\hline
\end{tabular}

${ }^{*} p<0.05 ;{ }^{* *} p<0.01 ;{ }^{* * *} p<0.001$.

†Hypertension: SBP $\geq 140$ or DBP $\geq 90$.

DVT, deep venous thrombosis; PE, pulmonary embolism; SVT, superficial venous thrombosis. 
Table 3 Venous events in studied population

\begin{tabular}{|c|c|c|c|c|}
\hline \multirow[b]{2}{*}{ Venous condition } & \multirow[b]{2}{*}{ All participants: N (\%) } & \multicolumn{3}{|l|}{ If } \\
\hline & & SVT: N (\%) & DVT: N (\%) & PE: N (\%) \\
\hline SVT & $63(2.68)$ & $63(100)$ & $5(22.7)$ & $2(13.3)$ \\
\hline DVT & 74 (3.09) & $5(8.33)$ & $74(100)$ & $11(52.4)$ \\
\hline $\mathrm{PE}$ & $21(0.87)$ & $2(3.17)$ & $11(14.9)$ & $21(100)$ \\
\hline Any deep event (DVT or PE) & $84(3.50)$ & $5(8.33)$ & $74(100)$ & $21(100)$ \\
\hline Any event (SVT or DVT or PE) & $142(5.91)$ & $63(100)$ & $74(100)$ & $21(100)$ \\
\hline
\end{tabular}

\section{Relationships among events}

The fraction of the population with superficial or deep venous events or $\mathrm{PE}$ is shown in table 3. A total of 142 had at least one type of thrombotic event (SVT, DVT or $\mathrm{PE}$ ), including 11 in whom both lower extremity (DVT) and pulmonary thrombotic events were reported. A total of 132 people had at least one SVT or DVT. Of these, 29 people reported bilateral events of one or both types, two citing both (data not shown in table).

More than half of those with a PE were aware of having had a DVT $(52.4 \%)$. This contrasts with only $2.65 \%$ of those without a PE being aware of a prior DVT, $14.9 \%$ of those with a DVT who had experienced a PE while only $0.43 \%$ of those with no reported DVT reported a PE. Thus, the expected relationship of DVT to PE (ie, increased likelihood of PE in the presence vs absence of reported DVT and vice versa) was upheld $\left(\chi^{2}=172.1\right.$, $\mathrm{p}<0.001)$.

A significant relationship ( $\chi^{2}$ analysis) was also seen between experiencing an SVT and a DVT $(p<0.001)$, as well as between experiencing an SVT and a PE $(\mathrm{p}=0.010)$.

\section{Multivariable analyses by event type}

SVT (table 4): Female sex, lower educational attainment, failure to specify level of maximum alcohol consumption, history of immobility and family history of firstdegree relatives with varicose veins showed significant (or for immobility, borderline significant, $\mathrm{p}<0.1$ ) positive relations, while African-American ethnicity appeared protective in the limited (age-sex) adjustment models. Each was significant in the final model.

DVT (table 5): For DVT, significance on multivariable regression was seen for heavy smoker status; history of immobility; and family history of first-degree relatives with DVE. In addition to these variables, Caucasian ethnicity, age and family history of superficial venous events appeared significant in the limited (age-sex) adjustment model, but lost significance on multivariable analysis.

$P E$ (table 5): For PE, significance on multivariable analysis was seen for: BP; history of immobility; and for women, duration of oestrogen use for HRT. Caucasian ethnicity and heavy smoking, with odds ratios (ORs) exceeding 2.5, were retained in the final model but did

Table 4 Multivariate analyses for SVT

\begin{tabular}{|c|c|c|c|}
\hline & $\begin{array}{l}\text { Age-sex adjusted* } \\
\text { OR ( } p \text { value) }\end{array}$ & $\begin{array}{l}\text { Fully adjusted } \\
\text { OR ( } p \text { value) }\end{array}$ & $\begin{array}{l}\text { Final model } \\
\text { OR ( } p \text { value) }\end{array}$ \\
\hline Age & $1.01(0.306)$ & $1.03(0.224)$ & - \\
\hline Male sex & $0.437(0.011)$ & $0.275(0.042)$ & $0.470(0.028)$ \\
\hline African-American ethnicity & $0.290(0.038)$ & $0.378(0.204)$ & $0.305(0.047)$ \\
\hline Education & $0.821(0.015)$ & $0.805(0.079)$ & $0.801(0.007)$ \\
\hline Activity level & $0.971(0.796)$ & $0.931(0.686)$ & - \\
\hline Heavy smoking ( $\geq 40$ cigarettes per day during time smoked) & $0.913(0.901)$ & $0.977(0.983)$ & - \\
\hline DBP (per $20 \mathrm{~mm} \mathrm{Hg})$ & $1.03(0.894)$ & $2.14(0.227)$ & - \\
\hline SBP (per $20 \mathrm{~mm} \mathrm{Hg}$ ) & $1.01(0.942)$ & $-\dagger$ & - \\
\hline $\begin{array}{l}\text { Drinkers who did not specify their maximum alcohol } \\
\text { consumption per day }\end{array}$ & $4.37(<0.001)$ & $4.65(0.011)$ & $3.33(<0.001)$ \\
\hline History of immobility (>1 day) & $1.55(0.091)$ & $2.53(0.015)$ & $1.71(0.043)$ \\
\hline $\begin{array}{l}\text { Family history of first-degree relatives with superficial } \\
\text { venous events }\end{array}$ & $1.54(0.301)$ & $1.55(0.520)$ & - \\
\hline Family history of first-degree relatives with varicose veins & $2.30(0.002)$ & $1.25(0.706)$ & $2.02(0.009)$ \\
\hline Family history of first-degree relatives with DVE & $1.74(0.177)$ & $1.25(0.637)$ & - \\
\hline
\end{tabular}


Table 5 Multivariate analyses for DVT, PE and combined deep venous events

\begin{tabular}{|c|c|c|c|c|c|c|c|c|c|}
\hline & \multicolumn{3}{|l|}{$\begin{array}{l}\text { DVT OR } \\
\text { ( } p \text { value) }\end{array}$} & \multicolumn{3}{|l|}{$\begin{array}{l}\text { PE OR } \\
\text { ( } p \text { value) }\end{array}$} & \multicolumn{3}{|c|}{$\begin{array}{l}\text { DVE (DVT and/or PE) OR } \\
\text { ( } p \text { value) }\end{array}$} \\
\hline & $\begin{array}{l}\text { Age-sex } \\
\text { adjusted }^{*}\end{array}$ & $\begin{array}{l}\text { Fully } \\
\text { adjusted }\end{array}$ & Final model & $\begin{array}{l}\text { Age-sex } \\
\text { adjusted }^{*}\end{array}$ & $\begin{array}{l}\text { Fully } \\
\text { adjusted }\end{array}$ & Final model & $\begin{array}{l}\text { Age-sex } \\
\text { adjusted }^{*}\end{array}$ & $\begin{array}{l}\text { Fully } \\
\text { adjusted }\end{array}$ & Final model \\
\hline Age & $1.02(0.047)$ & $1.05(0.162)$ & - & $1.02(0.404)$ & $0.977(0.621)$ & - & $1.03(0.004)$ & $1.04(0.202)$ & - \\
\hline Male sex & $1.01(0.955)$ & $0.479(0.312)$ & - & $1.41(0.435)$ & $0.778(0.795)$ & - & $1.15(0.548)$ & $0.773(0.662)$ & - \\
\hline Caucasian ethnicity & $2.35(0.003)$ & $0.754(0.674)$ & - & $2.68(0.083)$ & $5.77(0.149)$ & $2.58(0.096) \dagger$ & $2.26(0.003)$ & $0.936(0.913)$ & - \\
\hline Activity level & $0.827(0.059)$ & $0.819(0.418)$ & - & $0.771(0.163)$ & $0.986(0.971)$ & - & $0.846(0.081)$ & $0.909(0.672)$ & - \\
\hline $\begin{array}{l}\text { Heavy smoking ( } \geq 40 \\
\text { cigarettes per day during time } \\
\text { smoked) }\end{array}$ & $4.19(<0.001)$ & $10.1(0.007)$ & $16.6(<0.001)$ & $3.50(0.052)$ & $5.21(0.191)$ & $2.73(0.121) \dagger$ & $3.38(<0.001)$ & $6.92(0.013)$ & $12.5(<0.001)$ \\
\hline DBP (per 20 mm Hg) & $1.28(0.227)$ & $0.442(0.445)$ & - & $2.06(0.014)$ & $3.20(0.419)$ & $2.29(0.010) \S$ & $1.39(0.077)$ & $0.764(0.766)$ & - \\
\hline SBP (per $20 \mathrm{~mm} \mathrm{Hg}$ ) & $0.996(0.975)$ & $-\ddagger$ & - & $1.59(0.012)$ & $-\ddagger$ & $-\S$ & $1.05(0.643)$ & $-\ddagger$ & - \\
\hline $\begin{array}{l}\text { Drinkers who did not specify } \\
\text { their maximum alcohol } \\
\text { consumption per day }\end{array}$ & $1.74(0.170)$ & $1.46(0.739)$ & - & $1.63(0.534)$ & $2.70(0.447)$ & - & $1.61(0.235)$ & 1.09 (0.939) & - \\
\hline History of immobility (>1 day) & $2.17(0.001)$ & $5.32(0.008)$ & $4.30(0.006)$ & $4.44(0.002)$ & $4.21(0.114)$ & $4.07(0.004)$ & $2.23(<0.001)$ & $3.80(0.013)$ & $3.48(0.008)$ \\
\hline $\begin{array}{l}\text { Family history of first-degree } \\
\text { relatives with superficial } \\
\text { venous events }\end{array}$ & $3.32(0.024)$ & $0.719(0.643)$ & - & $1.51(0.600)$ & $0.730(0.754)$ & - & $2.52(0.036)$ & $0.626(0.449)$ & - \\
\hline $\begin{array}{l}\text { Family history of first-degree } \\
\text { relatives with DVE }\end{array}$ & $4.41(0.003)$ & $3.51(0.066)$ & $3.28(0.020)$ & $0.855(0.889)$ & $0.431(0.491)$ & - & $3.42(0.010)$ & $2.85(0.100)$ & $2.49(0.057)$ \\
\hline $\begin{array}{l}\text { Oestrogen use duration for } \\
\text { HRTी (per } 10 \text { years) }\end{array}$ & - & - & - & $2.73(0.000)$ & $3.73(0.000)$ & $2.63(0.001)$ & & & \\
\hline $\begin{array}{l}\text { Oestrogen use duration } \\
\text { among oestrogen users for } \\
\text { HRT (per } 10 \text { years) }\end{array}$ & - & - & - & - & - & - & $4.67(0.018)$ & $5.22(0.018)$ & $4.74(0.016)$ \\
\hline
\end{tabular}

Caucasian ethnicity shows significant relationship to DVT if not adjusted for family history of DVE (OR=2.15, $\mathrm{p}=0.008)$. If both Caucasian ethnicity and family history of DVE are included,

Caucasian ethnicity loses significance (OR 1.29, $p=0.659$ ) but family history of deep events retains significance (OR $3.17, p=0.026)$.

Age $(\mathrm{OR}=1.02, \mathrm{p}=0.035)$ and Caucasian ethnicity $(\mathrm{OR}=1.97, \mathrm{p}=0.015)$ show a significant relationship to combined deep events in the final model if family history of venous events is excluded. For combined DVT and/or PE, oestrogen use for HRT was tested as a predictor in women but was not significant. For oestrogen use duration (per 10 years), ORs ( $p$ values) for age-adjusted and final models were $0.532(0.534)$ and $0.523(0.611)$.

*Age variable was adjusted for sex only; and sex variable was adjusted for age only.

†Although some variables lose significance in the fully adjusted model due to collinearity, variables which were of significance or borderline significance in unadjusted or age/sex adjusted models were added back to the final model. When Caucasian ethnicity and heavy smoking were included without one another in the final model, they resumed significance or borderline significance.

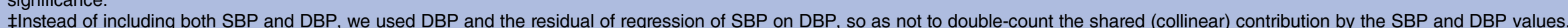

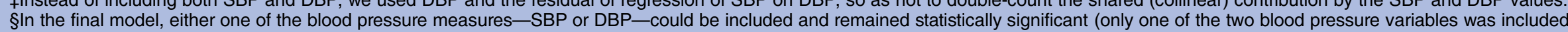
Sin the final model, either one of the blood pressure measures-SBP or DBP-could be included and remained statistically significant (only one of the two blood pressure variables was included because of collinearity)

ПFemale-specific analysis. Excludes family history of first deep events (see comment for PE). The final female-specific model included age and history immobilisation, the sole other variables with $\mathrm{p}<0.2$ (neither $<0.1$ ).

DBP, diastolic blood pressure; DVE, deep venous event; DVT, deep venous thrombosis; HRT postmenopausal hormone replacement therapy; OR, odds ratio; PE, pulmonary embolism; SBP, systolic blood pressure. 
not meet criteria for significance, reflecting the modest number of PEs $(n=21)$. We underscore that SBP and/or DBP, though not related to DVT or SVT in any adjustment scenario, were significantly related to $\mathrm{PE}$ on unadjusted and adjusted analyses.

DVE (DVT and/or PE; table 5): As for DVT, age and Caucasian ethnicity, though significant in the limited adjustment model, lost significance with further adjustment. Significance was seen for heavy smoker status and history of immobility. Family history of DVE, with an OR of 2.49, was also retained in the final model. This variable approached but did not meet criteria for significance $(\mathrm{p}=0.057)$.

\section{DISCUSSION}

This study characterises, in a population sample, the relationships between superficial and deep venous events, and between DVTs and PEs; it also characterises the risk correlates for SVT, DVT, PE and DVE. Some anticipated relationships were confirmed; and some intriguing differences in the statistical correlates of SVT versus DVT and for DVT versus PE were revealed.

The expected significant relationship between DVT and PE was upheld. ${ }^{12}$ There was also a significant relationship between risk of SVT and risk of DVT, as well as of $\mathrm{PE}$, as others have recently reported. ${ }^{13-16}$

Regarding sex differences, women were confirmed to have strongly and significantly higher rates of SVTs than men. Oestrogen use duration for HRT showed a link to DVE in women, consistent with existing findings. ${ }^{13}$ 17-19

History of heavy smoking was not associated with SVT, but was a strong risk factor for DVT and DVE. Smoking has been inconsistently reported as a risk factor for venous thrombosis, ${ }^{20}$ though it has been recognised to amplify risk in the setting of oral contraceptive use, ${ }^{21}$ perhaps contributing to its association to venous thromboembolism in studies of women of reproductive age. ${ }^{22}$ Moreover, some studies do report an association of smoking to venous thromboembolism extending to older samples and men as well as women. ${ }^{23} 24$

Caucasian ethnicity bore an apparent relationship to DVT, PE and DVE that was, however, extinguished with multivariable adjustment. The demographics of San Diego are such that ethnic minorities are more strongly represented in younger ages. Consistent with this, Caucasians were on average older than other study participants. Some other studies have also reported a relation of ethnicity to DVT to be extinguished with adjustment for other factors. ${ }^{25}$ Family history showed an association to DVT that is also consistent with existing documentation of genetic variation in venous thrombosis risk. ${ }^{17}$ 26-30

Immobility, a known risk factor for venous events, ${ }^{17} 19$ 31-36 was affirmed here to be a strong predictor for DVT, PE and DVE. It was also a predictor, though less potent, for superficial events. Many factors elsewhere reported to be associated with thrombosis entail periods of immobility: these range from nursing home confinement ${ }^{13}$ and hospitalisation, ${ }^{13} 2537$ to perisurgical, neurological and injury states; ${ }^{13} 253738$ factors also extend to prolonged sitting in the work environment. ${ }^{31-33} 35$

High maximum alcohol consumption was linked to DVT. High maximum alcohol use (such as binge drinking) is the pattern most linked to blackouts, ${ }^{39-41}$ and thus immobilisation. This alcohol finding coheres with a recent report of an association of venous thromboembolism to hard liquor consumption and binge drinking (contrasted with a protective association for wine consumption). ${ }^{42}$

We suggest, in addition, that many (if not most) risk factors for venous thromboembolism, those identified here and elsewhere, share in common an association to elevated risk of cell death, through oxidative stress or adverse cell energy supply-demand balance. Cell death is a consideration with immobilisation (leading to focal ischaemia), heavy smoking (oxidative stress ${ }^{43-45}$ triggers apoptosis ${ }^{46}$ ), heavy alcohol (promoting oxidative stress $^{4-50}$ and mitochondrial toxicity ${ }^{51-55}$ as well as ischaemia from immobilisation). Cancer, trauma, surgery and the puerperium are associated with tissue injury and cell death. Pregnancy is associated with diversion of blood and energy substrates to the fetus, as well as potential for ischaemic compression, which can promote cell death. We observe that cell death triggers coagulation activation, via exposure at the cell surface of phosphatidylserine, ${ }^{56}$ and hypothesise that ultimately numerous additional factors, sharing in common elevated risk of cell death (with oxidative stress and/or cell energy supply-demand frequently involved), or correlation to these, will be identified in the future as risk factors for venous thromboembolism. Indeed, the observation that initial DVT accompanied by $\mathrm{PE}$ is a risk factor for recurrence of $\mathrm{DVT}^{57}$ also fits this theme: PE, by affecting oxygen transfer, has prospects to tip the energy adequacy balance, particularly in settings of energy compromise from other sources. Also relevant, central obesity is linked to oxidative stress and cell energy inadequacy, ${ }^{58}$ and has shown a reported link to thromboembolism risk. $^{23}$

Perhaps the most novel findings from this analysis were that SBP and DBP, though unrelated to DVT, were strongly related to $\mathrm{PE}$. We suggest that given the absence of a relation of $\mathrm{BP}$, in this sample, to the requisite precursor event DVT, and given the measurement of BP after venous event occurrence, causality could operate in the reverse direction: PE, known to be a risk factor for pulmonary hypertension, ${ }^{59-64}$ could drive elevation in arterial BP. Indeed, transient hypoxaemia in other settings (such as sleep apnoea) promotes BP elevation. ${ }^{65-69}$ Even a modest reduction in oxygen transfer, arising from PE, might influence $\mathrm{BP}$ adversely-concordant with assembled evidence that a range of factors that impair cell energy promote hypertension (and other metabolic syndrome factors). ${ }^{58}$ Additional potentially compatible information derives from data that initial DVT accompanied by PE is a risk factor for recurrence 
of DVT; $;{ }^{57}$ and that arterial hypertension is a risk factor for recurrent $\mathrm{DVT}^{70}{ }^{2}$ which we hypothesise could be a marker for prior overt or occult PE.

Longitudinal studies assessing change in risk markers following events are seldom undertaken. Therefore, crosssectional designs' lack of 'temporality' may serve here not as a fault but as an advantageous feature, enabling event-factor as well as factor-event relations to be uncovered. However, prospective studies are desired to confirm hypothesised 'reverse' directionality. Irrespective of whether elevated BP ultimately proves to be a consequence of $\mathrm{PE}$, as we propose, the relationship will be important to understand.

This study has limitations, including those pertaining to all cross-sectional studies. Though the sample was diverse economically and ethnically, findings for this population need not generalise to all others; however, reproduction in this sample of many previously reported associations reduces concerns regarding the generalisability of the findings. The study measures historical occurrence rather than prospective incidence. Neither fatal events nor clinically silent ones were included in our analyses. Assessment is by self-report, which may involve recall and reporting bias; however, self-report of venous events has been used in other studies. ${ }^{71}$ In one study, it was shown that most self-reported DVTs were corroborated by a surgeon's assessment (via phone call), and concordance was particularly strong for PE. ${ }^{72}$ Most significantly, numerous associations identified here, both among venous outcomes and between risk factors and venous outcomes, cohere with associations reported in other studies using alternate event assessment modalities, providing strong convergent validation for the findings. An additional limitation, as in all observational studies, is inherent potential for omitted variable bias, which can influence the apparent relationship of tested variables to the outcome of interest. Most of the retained variables showed relationships robust across sensitivity analyses, supporting the relevance of the variables identified. Exceptions arose with inclusion/exclusion of ethnicity and family history. In this as in all studies, apparent ethnic and family relationships may represent proxies for (measured and) unmeasured variables with which ethnicity (or family) correlate. There were few cases of current cancer in our sample; elsewhere, cancer has been reported to predict venous events. ${ }^{13} 65{ }^{73-76}$ Finally, events had already occurred when risk markers were measured. For modifiable risk factors, the events could drive the factors rather than the converse, as discussed for the association of PE to increased SBP and DBP.

This study supports previously reported relationships of sex, history of immobility, heavy smoking and duration of HRT to venothrombotic events. It supports recent evidence for a relation of heavy maximal alcohol consumption to venous thromboses, consistent with prior evidence linking binge drinking to venous events. ${ }^{42}$ Family history was also affirmed to bear a strong relation to venous events, consistent with (but not exclusive to) recognised genetic risk factors. An intriguing association of $\mathrm{SBP}$ and $\mathrm{DBP}$ to $\mathrm{PE}$, but not to DVT, was identified. This novel finding is illuminated by, and simultaneously contributes to, an emerging body of evidence linking mediators of cell energy compromise to increased risk of hypertension-and to other metabolic syndrome factors. ${ }^{58}$ It is also observed, to the best of our knowledge for the first time, that factors promoting cell death-including factors that contribute to (or reflect) cell energy compromise or oxidative stress-may be expected to dispose to venous thromboembolism, explaining many observed risk factors ${ }^{23}$ and predicting numerous additional ones. ${ }^{58}$

Contributors MHC and BAG conceived the idea for the study. MHC acquired and provided the data. JOD managed data, developed the data dictionary and contributed to analysis review. VTC, BAG and SK conducted statistical analyses. The manuscript was drafted by BAG and VTC. All authors contributed to the revision of the manuscript for intellectual content and approved the final version of the manuscript.

Funding This research was funded by NIH-NHLBI grant 53487 and NIH GCRC Program grant M01 RR0827.

Competing interests None.

Ethics approval UCSD Human Research Protections Program.

Provenance and peer review Not commissioned; externally peer reviewed.

Data sharing statement No additional data are available.

Open Access This is an Open Access article distributed in accordance with the Creative Commons Attribution Non Commercial (CC BY-NC 3.0) license, which permits others to distribute, remix, adapt, build upon this work noncommercially, and license their derivative works on different terms, provided the original work is properly cited and the use is non-commercial. See: http:// creativecommons.org/licenses/by-nc/3.0/

\section{REFERENCES}

1. da Silva A, Widmer LK, Martin $\mathrm{H}$, et al. Varicose veins and chronic venous insufficiency. Vasa 1974;3:118-25.

2. Lafuma A, Fagnani F, Peltier-Pujol F, et al. [Venous disease in France: an unrecognized public health problem]. J Mal Vasc 1994;19:185-9.

3. Daver J. Socio-economic data on venous disease. Int Angiol 1984;3:84-6.

4. Goldhaber SZ. Venous thromboembolism: epidemiology and magnitude of the problem. Best Pract Res Clin Haematol 2012;25:235-42.

5. Stein PD, Matta F. Epidemiology and incidence: the scope of the problem and risk factors for development of venous thromboembolism. Clin Chest Med 2010;31:611-28.

6. Kurz X, Kahn SR, Abenhaim L, et al. Chronic venous disorders of the leg: epidemiology, outcomes, diagnosis and management. Summary of an evidence-based report of the VEINES task force. Venous Insufficiency Epidemiologic and Economic Studies. Int Angiol 1999;18:83-102.

7. Spyropoulos AC, Lin J. Direct medical costs of venous thromboembolism and subsequent hospital readmission rates: an administrative claims analysis from 30 managed care organizations. J Manag Care Pharm 2007;13:475-86.

8. Vekeman F, LaMori JC, Laliberte F, et al. Risks and cost burden of venous thromboembolism and bleeding for patients undergoing total hip or knee replacement in a managed-care population. J Med Econ 2011;14:324-34.

9. Baser O, Supina D, Sengupta N, et al. Clinical and cost outcomes of venous thromboembolism in Medicare patients undergoing total hip replacement or total knee replacement surgery. Curr Med Res Opin 2011;27:423-9. 
10. Kaplan RM, Criqui MH, Denenberg JO, et al. Quality of life in patients with chronic venous disease: San Diego population study. J Vasc Surg 2003;37:1047-53.

11. Criqui $\mathrm{MH}$, Jamosmos $\mathrm{M}$, Fronek $\mathrm{A}$, et al. Chronic venous disease in an ethnically diverse population: the San Diego Population Study. Am J Epidemiol 2003;158:448-56.

12. Ghaye B, Willems V, Nchimi A, et al. Relationship between the extent of deep venous thrombosis and the extent of acute pulmonary embolism as assessed by CT angiography. Br J Radiol 2009;82:198-203.

13. Heit JA. The epidemiology of venous thromboembolism in the community: implications for prevention and management. J Thromb Thrombolysis 2006;21:23-9.

14. Marchiori A, Mosena L, Prandoni P. Superficial vein thrombosis: risk factors, diagnosis, and treatment. Semin Thromb Hemost 2006;32:737-43.

15. Decousus $H$, Bertoletti $L$, Frappe $P$, et al. Recent findings in the epidemiology, diagnosis and treatment of superficial-vein thrombosis. Thromb Res 2011;127(Suppl 3):S81-5.

16. Hirmerova J, Seidlerova J, Subrt I. Deep vein thrombosis and/or pulmonary embolism concurrent with superficial vein thrombosis of the legs: cross-sectional single center study of prevalence and risk factors. Int Angiol 2013;32:410-16.

17. Cushman M. Epidemiology and risk factors for venous thrombosis. Semin Hematol 2007;44:62-9.

18. Sejersen HM, Nielsen HK, Thyssen JP, et al. [Deep venous thrombosis-epidemiology, diagnosis and treatment]. Ugeskr Laeger 2007;169:109-11.

19. Rosendaal FR. Venous thrombosis: the role of genes, environment, and behavior. Hematol Am Soc Hematol Educ Program 2005;2005:1-12.

20. Blondon M, Wiggins KL, McKnight B, et al. The association of smoking with venous thrombosis in women. A population-based, case-control study. Thromb Haemost 2013;109:891-6.

21. Pomp ER, Rosendaal FR, Doggen CJ. Smoking increases the risk of venous thrombosis and acts synergistically with oral contraceptive use. Am J Hematol 2008;83:97-102.

22. Worralurt C, Taneepanichskul S. Risk factors of venous thromboembolism (VTE) in Thai reproductive aged female: King Chulalongkorn Memorial Hospital experience. J Med Assoc Thai 2005;88:1502-5.

23. Hansson PO, Eriksson $\mathrm{H}$, Welin $\mathrm{L}$, et al. Smoking and abdominal obesity: risk factors for venous thromboembolism among middle-aged men: "the study of men born in 1913". Arch Intern Med 1999;159:1886-90.

24. Severinsen MT, Kristensen SR, Johnsen SP, et al. Smoking and venous thromboembolism: a Danish follow-up study. J Thromb Haemost 2009;7:1297-303.

25. Tan KK, Koh WP, Chao AK. Risk factors and presentation of deep venous thrombosis among Asian patients: a hospital-based case-control study in Singapore. Ann Vasc Surg 2007;21:490-5.

26. Milio G, Siragusa S, Mina C, et al. Superficial venous thrombosis: prevalence of common genetic risk factors and their role on spreading to deep veins. Thromb Res 2008;123:194-9.

27. Smith NL, Wiggins KL, Reiner AP, et al. Replication of findings on the association of genetic variation in 24 hemostasis genes and risk of incident venous thrombosis. J Thromb Haemost 2009;7:1743-6.

28. Smith NL, Hindorff LA, Heckbert SR, et al. Association of genetic variations with nonfatal venous thrombosis in postmenopausal women. JAMA 2007;297:489-98.

29. Gellekink H, Muntjewerff JW, Vermeulen $\mathrm{SH}$, et al. Catechol-O-methyltransferase genotype is associated with plasma total homocysteine levels and may increase venous thrombosis risk. Thromb Haemost 2007;98:1226-31.

30. Ahmad-Nejad P, Dempfle CE, Weiss C, et al. The G534E-polymorphism of the gene encoding the factor VII-activating protease is a risk factor for venous thrombosis and recurrent events. Thromb Res 2012;130:441-4.

31. Healy B, Levin E, Perrin K, et al. Prolonged work- and computer-related seated immobility and risk of venous thromboembolism. J R Soc Med 2010;103:447-54.

32. West J, Perrin K, Aldington S, et al. A case-control study of seated immobility at work as a risk factor for venous thromboembolism. $J$ R Soc Med 2008;101:237-43.

33. Aldington S, Pritchard A, Perrin K, et al. Prolonged seated immobility at work is a common risk factor for venous thromboembolism leading to hospital admission. Intern Med J 2008;38:133-5.

34. Gaber TA. Significant reduction of the risk of venous thromboembolism in all long-term immobile patients a few months after the onset of immobility. Med Hypotheses 2005;64:1173-6.
35. Beasley R, Raymond N, Hill S, et al. eThrombosis: the 21st century variant of venous thromboembolism associated with immobility. Eur Respir J 2003;21:374-6.

36. Farzamnia $\mathrm{H}$, Rabiei $\mathrm{K}$, Sadeghi $\mathrm{M}$, et al. The predictive factors of recurrent deep vein thrombosis. ARYA Atheroscler 2011;7:123-8.

37. Nakamura M, Sakuma M, Yamada N, et al. Risk factors of acute pulmonary thromboembolism in Japanese patients hospitalized for medical illness: results of a multicenter registry in the Japanese society of pulmonary embolism research. J Thromb Thrombolysis 2006;21:131-5.

38. Medda P, Fornaro M, Fratta S, et al. A case of deep venous thrombosis following protracted catatonic immobility recovered with electroconvulsive therapy: the relevance for an early intervention. Gen Hosp Psychiatry 2012;34:209 e5-7.

39. Delk EW, Meilman PW. Alcohol use among college students in Scotland compared with norms from the United States. J Am Coll Health 1996;44:274-81.

40. Kypri K, Paschall MJ, Langley J, et al. Drinking and alcohol-related harm among New Zealand university students: findings from a national Web-based survey. Alcohol Clin Exp Res 2009;33:307-14.

41. Read JP, Wardell JD, Bachrach RL. Drinking consequence types in the first college semester differentially predict drinking the following year. Addict Behav 2013;38:1464-71.

42. Hansen-Krone IJ, Braekkan SK, Enga KF, et al. Alcohol consumption, types of alcoholic beverages and risk of venous thromboembolism-the Tromso Study. Thromb Haemost 2011;106:272-8.

43. Mesaros C, Arora JS, Wholer A, et al. 8-Oxo-2'-deoxyguanosine as a biomarker of tobacco-smoking-induced oxidative stress. Free Radic Biol Med 2012;53:610-17.

44. Talukder MA, Johnson WM, Varadharaj S, et al. Chronic cigarette smoking causes hypertension, increased oxidative stress, impaired NO bioavailability, endothelial dysfunction, and cardiac remodeling in mice. Am J Physiol Heart Circ Physiol 2011;300: H388-96.

45. Grassi D, Desideri G, Ferri L, et al. Oxidative stress and endothelial dysfunction: say NO to cigarette smoking! Curr Pharm Des 2010;16:2539-50.

46. Takahashi A, Masuda A, Sun M, et al. Oxidative stress-induced apoptosis is associated with alterations in mitochondrial caspase activity and $\mathrm{Bcl}-2-d e p e n d e n t$ alterations in mitochondrial $\mathrm{pH}(\mathrm{pHm})$. Brain Res Bull 2004;62:497-504.

47. Haorah J, Ramirez SH, Floreani N, et al. Mechanism of alcohol-induced oxidative stress and neuronal injury. Free Radic Biol Med 2008;45:1542-50.

48. Das SK, Vasudevan DM. Alcohol-induced oxidative stress. Life Sci 2007;81:177-87.

49. Albano E. Alcohol, oxidative stress and free radical damage. Proc Nutr Soc 2006;65:278-90.

50. Wu D, Cederbaum Al. Alcohol, oxidative stress, and free radical damage. Alcohol Res Health 2003;27:277-84

51. Reddy VD, Padmavathi P, Kavitha G, et al. Alcohol-induced oxidative/nitrosative stress alters brain mitochondrial membrane properties. Mol Cell Biochem 2013;375:39-47.

52. Almansa I, Fernandez A, Garcia-Ruiz C, et al. Brain mitochondrial alterations after chronic alcohol consumption. J Physiol Biochem 2009;65:305-12.

53. Mantena SK, King AL, Andringa KK, et al. Mitochondrial dysfunction and oxidative stress in the pathogenesis of alcohol- and obesity-induced fatty liver diseases. Free Radic Biol Med 2008;44:1259-72.

54. Cederbaum Al. Effects of alcohol on hepatic mitochondrial function and DNA. Gastroenterology 1999;117:265-9.

55. Gordon ER. Alcohol-induced mitochondrial changes in the liver. Recent Dev Alcohol 1984;2:143-58.

56. Reutelingsperger CP, van Heerde WL. Annexin V, the regulator of phosphatidylserine-catalyzed inflammation and coagulation during apoptosis. Cell Mol Life Sci 1997;53:527-32.

57. Christiaens L. [Idiopathic venous thromboembolic disease. risk factors for recurrence in 2006]. Arch Mal Coeur Vaiss 2007;100:133-8.

58. Golomb BA. The starving cell: metabolic syndrome as an adaptive process. Nat Precedings 2011. http://precedings.nature.com/ documents/6535/version/1

59. McCabe C, Deboeck G, Harvey I, et al. Inefficient exercise gas exchange identifies pulmonary hypertension in chronic thromboembolic obstruction following pulmonary embolism. Thromb Res 2013;132:659-65.

60. Barros A, Baptista R, Nogueira A, et al. Predictors of pulmonary hypertension after intermediate-to-high risk pulmonary embolism. Rev Port Cardiol 2013;32:857-64. 
61. Morris TA. Why acute pulmonary embolism becomes chronic thromboembolic pulmonary hypertension: clinical and genetic insights. Curr Opin Pulm Med 2013;19:422-9.

62. Klok FA, Mos IC, van Kralingen KW, et al. Chronic pulmonary embolism and pulmonary hypertension. Semin Respir Crit Care Med 2012;33:199-204.

63. Berghaus TM, Barac M, von Scheidt W, et al. Echocardiographic evaluation for pulmonary hypertension after recurrent pulmonary embolism. Thromb Res 2011;128:e144-7.

64. Poli D, Miniati M. The incidence of recurrent venous thromboembolism and chronic thromboembolic pulmonary hypertension following a first episode of pulmonary embolism. Curr Opin Pulm Med 2011;17:392-7.

65. Sugimura K, Sakuma M, Shirato K. Potential risk factors and incidence of pulmonary thromboembolism in Japan: results from an overview of mailed questionnaires and matched case-control study. Circ J 2006;70:542-7.

66. Coy TV, Dimsdale JE, Ancoli-Israel S, et al. The role of sleep-disordered breathing in essential hypertension. Chest 1996;109:890-5.

67. Hargens TA, Nickols-Richardson SM, Gregg JM, et al. Hypertension research in sleep apnea. J Clin Hypertens (Greenwich) 2006;8:873-8.

68. Lin QC, Deng CS, Ding HB, et al. [Effects of long term nasal continuous positive airway pressure on the blood pressure of patients with obstructive sleep apnea hypopnea syndrome]. Zhonghua Jie He He Hu Xi Za Zhi 2012;35:687-90.
69. He QY, Feng J, Zhang XL, et al. Elevated nocturnal and morning blood pressure in patients with obstructive sleep apnea syndrome. Chin Med J (Engl) 2012;125:1740-6.

70. Linnemann B, Zgouras D, Schindewolf M, et al. Impact of sex and traditional cardiovascular risk factors on the risk of recurrent venous thromboembolism: results from the German MAISTHRO Registry. Blood Coagul Fibrinolysis 2008;19:159-65.

71. Wu EC, Barba CA. Current practices in the prophylaxis of venous thromboembolism in bariatric surgery. Obes Surg 2000;10:7-13; discussion 14

72. Greenbaum JN, Bornstein LJ, Lyman S, et al. The validity of self-report as a technique for measuring short-term complications after total hip arthroplasty in a joint replacement registry. J Arthroplasty 2012;27:1310-15.

73. Ahlbrecht J, Dickmann B, Ay C, et al. Tumor grade is associated with venous thromboembolism in patients with cancer: results from the Vienna Cancer and Thrombosis Study. J Clin Oncol 2012;30:3870-5.

74. Lauw MN, van Doormaal FF, Middeldorp S, et al. Cancer and venous thrombosis: current comprehensions and future perspectives. Semin Thromb Hemost 2013;39:507-14.

75. Araujo A. [Cancer and deep venous thrombosis: the purpose of the CATCH clinical trial]. Acta Med Port 2013;26:83-5.

76. Timp JF, Braekkan SK, Versteeg HH, et al. Epidemiology of cancerassociated venous thrombosis. Blood 2013;122:1712-23. 